Marquette University

e-Publications@Marquette

$3-1-2013$

Economics Imperialism under the Impact of Psychology: The Case of Behavioral Development Economics

John B. Davis

Marquette University, john.davis@marquette.edu

Published version. OEconomia, Vol. 2013, No. 1 (March 2013): 119-138. Publisher Link. (C) 2013

NecPlus. Used with permission. 


\title{
Economics imperialism under the impact of psychology: The case of behavioral development economics
}

\author{
John B. Davis \\ Department of Economics \\ Marquette University
}

\begin{abstract}
.
Economics imperialism is broadly explained as economics having an impact on other disciplines. But how should economics imperialism be understood when it is in some sense the product of other disciplines having an impact on economics? The paper examines psychology's impact on economics in connection with the emergence of behavioral development economics, and then discusses the nature of behavioral development economics imperialism associated with development economists' explanations of non-market dimensions of life in developing economies in behavioral economics terms. The paper argues that this new form of economics imperialism reflects economics' selective appropriation from psychology of the KahnemanTversky heuristics and biases view of choice behavior and rejection of the Gigerenzer-ABC group fast and frugal heuristics view. This selective appropriation, however, causes behavioral development economics imperialism to also function as a social and cultural imperialism since its utility theory-based policy recommendations impose liberal society economic values on developing economy societies. Thus recent economics-plus-psychology imperialism might be said to function as social science imperialism under the leadership of economics
\end{abstract}

JEL Classification A14, O10, B2, B41

Keywords: economics imperialism, choice heuristics, behavioral development economics

February 2013

\footnotetext{
- Corresponding author

Email: john.davis@marquette.edu
} 
Economics imperialism has been an important subject of investigation in the philosophy of economics and economic methodology since Gary Becker's extension of neoclassical economic reasoning to nonmarket social domains, long the province of other social sciences, generated new questions regarding the scope and nature of economics. Among the methodological issues investigated were whether economics imperialism can be understood in Kuhnian terms (Fine, 2001, 2002) and whether it achieved or failed to achieve explanatory unification across disciplinary boundaries (Mäki, 2009). However, while these discussions of economics imperialism mostly put aside whether economics is also subject to imperialistic incursions from other sciences, that issue needs to be investigated since clearly other disciplines have had an impact on economics as game theory, behavioral economics, experimentalism, evolutionary economics, agent-based modeling, and other new approaches in economics all have their origins outside of economics. Note, then, that this significantly complicates the analysis of economics imperialism because it makes it unclear what economics' identity is if its explanations rely on elements from other sciences which carry important weight relative to traditional economics concepts and principles (Davis, 2012). For example, an early extension of Becker's economics of the family went beyond neoclassical reasoning in using game theory to explain intra-household bargaining (Manser and Brown, 1980; McElroy and Horney, 1981). Was this economics imperialism or was it an imperialism of mathematics (where game theory originated) merely in transit through economics subsequent to its own imperialism into economics? ${ }^{1}$

What the post-1980s history of economics thus tells us about economics imperialism is that prior to making any claims about economics having transformative effects on other sciences we need to investigate if other sciences have had transformative effects on economics. But how does one go about doing this? Suppose we begin by first making the assumption that economics has retained its relative autonomy as a science despite the influence of other sciences upon it. Then one way to explain this is to say that other science contents that enter into economics need to be seen as being selectively appropriated or 'domesticated' in ways that somehow maintain economics' separate identity as a science (though this could also be compatible with change in the definition and some of the main concerns of economics, perhaps even so much so as to depart from the neoclassical pre-1980s Lionel Robbins conception of the field). This appropriation/domestication process arguably then proceeds through a series of debates and contests within economics over which concepts and principles from other fields ought to be regarded as enlarging traditional economic explanations. For example, experimental research in economics under the impact of evidence from social psychology showing that people often cooperate has revolved in good part around debates over how or whether this evidence can be understood in terms of the principle of individual utility maximization (Fehr and Schmidt, 1999). An important aspect of debates such as these, then, is that they tend to ignore or even suppress

\footnotetext{
${ }^{1}$ Herbert Simon suggested this kind of view: "The most salient fact in the postwar history of economics was its sudden conquest by mathematics and statistics .... I think it could be said that by 1970 mathematics had taken over economics (for better or worse); the simplest theory had to be clothed in mathematical garb before it could receive any serious attention, and 'empirical work' was synonymous with 'econometrics'” (Simon, 1991, pp. 325$6)$.
} 
important debates taking place in other sciences regarding the meaning of the concepts being absorbed into economics, particularly with respect to interpretations of these concepts which are not easily accommodated in economics. For example, though cooperation can be explained in terms of people identifying with others despite it not being in their own interest (Sen, 1985) the dominant interpretation of social identity in economics explains it in terms of utility maximization (Akerlof and Kranton, 2000). Thus, the selective appropriation process generally allows concepts and principles to travel across disciplinary boundaries but is likely to screen out certain interpretations of them as well as entire debates elsewhere about their meaning and significance. ${ }^{2}$

Suppose we also assume that debates in economics about the value and relevance of other science contents to economics acquire special significance when they take place in applied fields in economics. That is, debate over what other sciences can contribute to economics acquires particular clarity and decidability for economists when the candidate concepts are applied in concrete explanatory contexts where procedures for their empirical investigation are available and potential policy implications are at issue. For example, game theory acquired significant credibility in economics conceptually and as an important tool of analysis after it was used to explain market power dynamics in the field of industrial organization (see Schmallensee, 1988). In effect, 'realism' counts when economists are forced to confront the question of whether their subject has practical value for others in the policy world (particularly when there is skepticism about what economics has to offer), compelling them to make sharper judgments regarding which concepts and principles they ought to employ, whatever their disciplinary origins. ${ }^{3}$

This paper employs these two assumptions to investigate one recent case of economics imperialism explained as the product of the recent influence of psychology on economics and economics' selective appropriation of a set of concepts from psychology concerning the cognitive nature of individual decision making. The paper argues, first, that an active debate in psychology between two views of choice heuristics, the heuristics and biases/prospect theory approach of Daniel Kahneman and Amos Tversky and the fast and frugal heuristics/adaptive toolbox approach of Gerd Gigerenzer and the ABC research group, has been largely ignored in economics due to its adoption of the former approach in virtue of its conformability to utility maximization reasoning, and, second, that this adoption has produced a behavioral development economics imperialism which targets a wide range of behaviors in developing nations customarily regarded as non-economic (for example, use of bed nets at home to prevent malaria). It is further argued that this new economics-plus-psychology imperialism - a social science imperialism under the leadership of economics - is also a social and cultural imperialism, because development economists' policy recommendations when based on behavioral economics' utility theory reasoning apply advanced country liberal values and conceptions regarding how societies

\footnotetext{
${ }^{2}$ A separate issue not addressed here concerns debates regarding which contents from different sciences can be accommodated to economics' distinctive explanatory goals, for example, whether ideas from game theory or psychology are better able to explain choice behavior.

${ }^{3}$ This has been claimed as an important justification for behavioral economics. For example, Camerer (2006) argues that behavioral economics has many potential applications.
} 
ought to function to countries where those values are either absent or compete with different values and conceptions of society. ${ }^{4}$

The balance of this paper is organized as follows. The second section of the paper briefly distinguishes and compares the two different approaches in psychology to the cognitive nature of individual decision making: the heuristics and biases/prospect theory approach of Kahneman and Tversky (the 'new' or modern behavioral economics) and the fast and frugal heuristics/adaptive toolbox approach of Gigerenzer and the Adaptive Behavior and Cognition $(A B C)$ research group (the 'old' or classical behavioral economics following the thinking of Herbert Simon ${ }^{5}$ ). It then argues that the KahnemanTversky approach has been adopted by economists because it assumes that rational behavior in the standard sense is a normative ideal which can in principle be realized through proper policy design of choice architectures. The third section discusses how behavioral development economics draws on the Kahneman-Tversky heuristics and biases approach. The poor are said to be unable to escape poverty because their cognitive biases put them at greater risk than the non-poor. But if policies aimed at changing their 'default' choices can be designed, they can be 'nudged' toward rational choices which would improve their welfare. The fourth section argues that behavioral development economics is an economics/social science imperialism which is also a social and cultural developed country imperialism that operates especially through the channel of the advanced country expert policy advisors. Central to the argument is how the meaning of policy paternalism espoused by behavioral economists differs between developed and developing economy societies. The fifth and concluding section discusses the idea of a social science imperialism under the leadership of economics, and recommends it as an improvement on the traditional economics imperialism idea.

\section{The psychologists' debate: Prospect theory versus the adaptive toolbox}

Fundamental to the difference between psychology's prospect theory approach of Kahneman and Tversky and the adaptive tool box approach of Gigerenzer and the $A B C$ research group are two quite different conceptions of the nature of heuristics, seen by both as characteristic features of human decision-making. For Kahneman and Tversky and their followers, heuristics are regarded as cognitive biases that distort rational decision-making, that is, as perceptual and inferential mechanisms tied to the human make-up that prevent individuals from making fully rational or utility maximizing choices. A long list of such mechanisms has been extensively investigated by both psychologists and economists (see Gilovich, Griffin, and Kahneman, 2002). Prospect theory as a theory of choice itself employs an individual value function - regarded as a psychologically more realistic analogue to the standard rational choice theory individual utility function - that is expressed in terms of two scales: one which assigns weights to different types of probabilities, whereby people overreact to small probability events and

\footnotetext{
${ }^{4}$ It should be noted that Gigerenzer-ABC group may be keener to distinguish itself from the Kahneman-Tversky approach than the reverse. Yet the latter has not altogether hesitated to claim distinctiveness for its approach (cf. Kahneman and Tversky, 1996).

${ }^{5}$ For Simon's orientation and influence, see Velupillai and Ying Fang (forthcoming).
} 
underreact to medium and large probability events, and a second scale which assigns subjective value to prospects relative to choice reference points, whereby people are risk-averse with respect to gains and risk-seeking with respect to losses. Standard theory utility functions are then reclassified as normative or idealized explanations of choice, while the individual value function of prospect theory is characterized as a descriptive representation of the choices that people actually make (Thaler, 2000; see Heukelom, 2011). An implication of this is that properly designed choice architectures (Thaler and Sunstein, 2008), a policy-driven construction of the settings in which people make choices, should in principle make it possible for people to choose in a nearly rational way, that is, as if they had complete information about the consequences of their choices and were able to compensate for their cognitive biases. Thus standard rational choice theory functions as a central point of reference for prospect theory not only as a normative ideal but also as a potentially realizable state of affairs that could be brought about by active policy intervention. The understanding of choice heuristics in the Kahneman and Tversky approach is accordingly a matter of explaining imperfections in human behavior which could be corrected in such a manner as to allow people to act in a utility maximizing way.

The understanding of choice heuristics on the part of Gigerenzer and the ABC research group (e.g., Gigerenzer and Selten, 2001) is quite different. Fast and frugal heuristics, as they are called, are seen to be simple cognitive rules or procedures that human beings employ to make choices in uncertain environments which dispense with the need for complete information and for the decision-maker to have a high degree of computational capacity. They are not cognitive biases which limit rational decision making in the standard sense as for Kahneman and Tversky, but rather rational and efficient means of making choices in the form of cognitive tools specifically adapted to the occasion of choice. That is, following Simon's understanding of bounded rationality (e.g., Simon, 1956) fast and frugal heuristics are procedurally or ecologically rational rather than substantively rational. As such, they do not incorporate the utility values and probability measures of standard rationality theory. This means that in contrast to Kahneman and Tversky's view that standard rationality theory is normative but unrealistic, for Gigerenzer and the $\mathrm{ABC}$ group standard theory operates with an altogether incorrect view of rationality, much less one that has normative value, while the heuristics and biases approach provides an unrealistic explanation of human decision-making. The root of the difference between the two views of heuristics thus comes down to their opposed views of standard rationality - a difference that can be explained in terms of two different conceptions of the kind of search process which the decision-maker engages in prior to choice. For Kahneman and Tversky, the search process is a matter of locating an expected utility optimum, where that search process is obstructed by a multitude of perceptual and inferential biases. For Gigerenzer and the $A B C$ group, the search process is understood as a problem-solving activity, and the heuristics decision-makers employ are useful shortcuts that selectively guide the search for solutions to those problems. Thus the 'fast and frugal' idea may also be expressed by the idea that 'less is more' - less information requirements and less needed computational capacity makes for more effective decision-making. In general, then, social policies intended to improve decision-making opportunities must be sensitive to the concrete circumstances of choice, and attentive to how people actually solve decision problems. Their established heuristics are likely to be adaptive to their circumstances, and not in need of correction. 
Given that the Kahneman-Tversky and the Gigerenzer-ABC group approaches differ substantially in regard to their interpretation of the nature of decision heuristics, it is also worth comparing them in regard to their different views of what a decision-maker is, or what a person is, especially as this is relevant to their different implications for the application of psychological thinking in the applied economics field of development economics. Indeed here there is also a fundamental contrast. Since standard rationality theory is for Kahneman and Tversky the way decision-makers ideally behave, it follows that people are essentially utility maximizing beings, meaning that they are defined as collections of subjective preferences. Saying a preference is 'subjective' means that it is a motivation which is unconditioned by the circumstances which occasion its expression (such as changes in prices and incomes). That is, preference affects choice, but there is no feedback effect from the individual's choice upon the preferences that motivated that choice. Standard theory does allow that individuals' preferences can change, but not as a result of individual decision-making. Indeed, preference change is left unexplained in standard theory. This not only secures the autonomy of the individual so central to liberal economics, but also means that individuals defined as collections of subjective preferences are incapable of learning about what motivates their choices. ${ }^{6}$

In the case of Gigerenzer and the $A B C$ group, rationality is explaining as ecological rationality in order to emphasize how individuals constantly adapt their decision-making to the changing circumstances of choice. On this view, individuals are thus not collections of preferences but are rather collections of rules and procedures that they revise according to their relative adequacy - or 'satisficing' character, as Simon expressed it. Thus they are not purely subjective beings, but through the feedback effects their choices have upon them are intimately embedded in the world, and thereby rather have what can be termed in contrast to the standard view an individuality that constantly evolves in its content and makeup (Davis, 2012, pp. 142ff). One thing this implies is that as adaptive beings the choices they make are reflective of the contexts in which they are made. This multiplies the variety of motivations they have, and makes it difficult to identify a predictable list of incentives to ascribe to them. This, we will see, is a key factor in regard to how these two types of psychological approaches can be employed in applied fields in economics, such as development theory, since they provide quite different views regarding how people's behavior ought to be interpreted in concrete decision settings. Indeed, this is especially important in the field of development economics since there are important differences between developing and developed economies with respect to social-economic contexts in which people make choices. How, then, has behavioral economics made its way into the applied field of development economics?

\section{Behavioral Development Economics}

\footnotetext{
${ }^{6}$ Though they do learn in a Bayesian sense in regard to information about the world - a matter external to the individual.
} 
Central to behavioral development economics is a new view of why people are in poverty in developing economies, and thus a new view of how it is possible for the poor to 'escape' poverty. One traditional view on the subject is that the persistence of poverty is explained by a 'culture of poverty' which causes people to behave irrationally by the standards of people not in poverty, basically because their values and choices are distorted by living in poor communities (Lewis, 1969). But behavioral development economists deny that the poor are any less rational than the non-poor. As Abhijit Banerjee and Esther Duflo emphasize in their influential Poor Economics, the poor are little different from the non-poor since they exhibit the same cognitive weaknesses and biases which behavioral economists have studied in people generally.

What is striking is that even people who are poor are just like the rest of us in almost every way. We have the same desires and weaknesses; the poor are no less rational than anyone else quite the contrary (Banerjee and Duflo, 2011, p. ix)

The difference between the poor and non-poor, then, is that "in poverty, with its narrow margins for error, the same behaviors often manifest themselves in more pronounced ways that can lead to worse outcomes" (Bertrand, Mullainathan, Shafir, 2004; also see Bertrand, Mullainathan, Shafir,2006). That is, the conditions of poverty magnify the effects of people's cognitive weaknesses and biases. These conditions include lack of bank accounts, scarce health facilities, unreliable water supplies, high teacher absence rates, poor transportations systems, etc., which are usually not concerns for the non-poor, and thus do not expose them to the costs of ordinary biased decision-making. But this also means there is good reason to believe that they might 'escape' poverty should it be possible to alter their choice circumstances in ways which reduce the scope of the ill effects that their cognitive weaknesses and biases have on them in particular. The research strategy this then implies is that development economists ought to: (1) investigate how the poor make biased choices that affect their economic wellbeing, and then (2) design and recommend institutional arrangements that correct for their decisionmaking in ways that allow them to make rational, welfare-enhancing choices which would allow them to accumulate wealth and human capital sufficient to escape poverty.

Regarding (1), how the poor make choices, Richard Thaler's mental accounting view of cognitive behavior has been influential. Thaler argues that people compartmentalize their thinking about spending into distinct budget categories, such as housing, education, food, and savings, and ignore rational trade-offs between them (Thaler, 1999). Their budgeting decisions, in effect, 'default' to choices that reflect predetermined, fixed relationships between these categories. One especially important cognitive bias that produces undesirable default-type choices with respect to current spending and saving for the future is time inconsistent behavior, as manifested in the tendency people have to continually procrastinate and postpone actions that they plan to undertake in the future. People behave time inconsistently when they value the present more highly than the future (employing what are called hyperbolic time discount rates), and default to current spending, thereby always postponing the saving which would improve their long-run economic circumstances. Economists, however, judge it to be rational to value all periods in the same way (thus preferring that people use exponential time discount rates). People would then be time consistent, would adequately save for the 
future, and would think beyond their customary compartmentalization of their spending and saving decisions.

Regarding (2), how institutions can be designed to correct for biased decision-making, the idea is to replace poor people's customary default choices by rational ones.

An important idea is that of default option: The government (or a well-meaning NGO) should make the option that it thinks is the best for most people the default choice, so that people will need to actively move away from it if they want to. So people have the right to choose what they want, but there is a small cost of doing so, and as a result, most people end up choosing the default option (Banerjee and Duflo, 2011, p. 66).

As the product of decision heuristics, default choices are easy choices, and thus costly to circumvent. What institutional design can accomplish, then, is to use the logic of default choice against irrational choice by making it costly for people to behave time inconsistently. An example is setting up electronic bank deposits for government transfers to the poor (Bertrand, Mullainathan, Shafir, 2004, pp. 420-1). This can stimulate recipients to save out of income, since once the account is in place its holder sees how savings can accumulate, and must also take additional steps to spend down its balance in accessing the account (Benartzi and Thaler, 2004). Following the argument of Thaler and Cass Sunstein (2008), this is the policy idea of constructing a collection of institutional "'nudges' tailored to the environment of developing countries" (Banerjee and Duflo, Ibid.). Against the charge that 'nudge' policy is paternalist and interferes with people's freedom, the response is that the "small cost" approach is one that in fact respects people's freedom, since they are not compelled to act in a time consistent manner, and still have "the right to choose what they want." People's choice incentives are indeed changed by economic policies, but this has always been the case with policy interventions in the economy.

Behavioral development economics, then, not only derives its main theoretical assumptions from the Kahneman-Tversky heuristics and biases approach, but it also extends that analysis, drawing concrete policy conclusions from it for developing economies. For comparison, consider the view of policy implied by the Gigerenzer-ABC group fast and frugal heuristics approach. Fast and frugal heuristics are decision-making rules that are generally well adapted to the circumstances of choice, in that they require limited computational capacity and make it possible for people to contend with a high degree of uncertainty. As useful shortcuts, they selectively guide search to produce solutions to decision problems that are ecologically rational, implying that were one to 'correct' them by changing people's decision defaults, one could actually inject bias into their decision-making, making it ecologically irrational, rather than remove it. At the same time, adopting a fast and frugal heuristics approach does not mean that there is no space for policies aimed at improving social well-being. For example, differences between countries regarding organ donation rates have been shown to reflect how people differ in their 'default heuristics' with regard to organ donation, and that these 'default heuristics' often reflect various government policies, some recognized and some not (Gigerenzer, 2010). Thus policies designed to raise organ donation rates would not aim at government 'nudging' individuals to act differently but rather at changes in government rules and practices which cause individuals to default to certain behaviors. What particular policies this involves goes beyond the topic of this paper. Policy questions are often 
complicated requiring careful empirical research. What the next section turns to, then, is how we might evaluate the effects of economics' selective appropriation of ideas from psychology in connection with the idea of a behavioral development economics imperialism.

\section{Behavioral Development Economics Imperialism}

In the first section of this paper it was assumed that economics, like other social science disciplines, has retained a relative autonomy as a science, despite its extensive adoption since the 1980s of a variety of concepts and principles from other sciences. The basis for that assumption is the idea that economics is selective in its appropriation of other science contents, and selective in such a way as to ensure that its overall organization of theoretical concerns and arguments remains 'economic.' On one level, for the field to sustain an investigation of the 'economic' in this way simply involves its continuing to address issues that have generally occupied it across the history of economics - issues such as how prices are determined, the sources of income and wealth, how markets work, what economic well-being involves, etc. On a second level, however, for the field to continue to be concerned with what is 'economic' is a matter of largely maintaining its current view of what that idea involves, namely, the allocation of scarce resources focus, the principle that this occurs largely through markets, a general reliance on static analysis, and its rationality view of economic behavior, in particular, that people are utility maximizing decision-makers. So economics retaining a relative autonomy as a science from this two-level perspective means that its appropriation of other science contents needs to respect these past and recent boundaries. Consider, then, what this implies for the way in which psychology must enter into economics, and how this transforms economics imperialism.

In effect, if economics' adoption of other science contents is selective in the way suggested above, then it needs to carry out an 'in-house' economics imperialism with respect to any non-economic contents that are prospective candidates for absorption into economics. Psychology's heuristics understanding of human decision-making, as a specifically cognitive approach rather than a rational choice approach, is as such a non-economic view of choice behavior. Thus for it to be absorbed into economics its noneconomic character must be somehow re-interpreted as economic, which we have seen has been accomplished in behavioral economics by explaining decision heuristics as biases from rational behavior. This 'in-house' economics imperialism thus involves the same principle of operation as has traditionally been understood to operate with economics imperialism except for the fact that the non-economics content which is subject to reframing as 'economic' is now examined directly on the terrain of economics rather than on the terrain of another science discipline. ${ }^{7}$ It might be argued, then, that this appropriation process could jeopardize the integrity of economics, because it is not clear whether psychological concepts are being reinterpreted as 'economic' or the reverse. But if we take the relative autonomy assumption and the domestication argument seriously, then rather than being jeopardized by

\footnotetext{
${ }^{7}$ I expand on this 'in-house' argument (without using that expression) in terms of a core-periphery model of economics as a discipline in Davis (2012). The argument is that within economics different research programs compete or sometimes simply function in parallel in disregard for one another in the non-core, periphery space of economics where other science ideas and principles are advanced and tested as candidate contents for economics.
} 
its imports from other disciplines economics ought to be seen as reinforcing its main commitments. This implies an important difference with the earlier economics imperialism of Becker. If that imperialism was an inherently difficult project in virtue of needing to impose a foreign content on the other science domains to which economics was being applied, by contrast a behavioral economics imperialism seems to be a project with a reasonable prospect of succeeding because it brings an originally non-economic content (from psychology) to bear on whatever science domain to which it is applied - albeit after that non-economic content has been reframed as 'economic.' That is, because what behavioral economics seeks to apply elsewhere is less apparently 'economic' in its guise as economics made more realistic by psychology, its foreign character for the fields to which it is being applied is mitigated. But appearances in this case are deceiving since behavioral economics following Kahneman and Tversky is still standard rationality theory under utility maximization. Thus this new economics imperialism still fits the standard definition whereby non-economic domains are re-interpreted in terms of economic ideas and principles.

What are the non-economic domains, then, which behavioral development economists target if they are to be characterized as imperialist? Here it is helpful to see how behavioral development economics fits in to the recent history of development economics. Not only, then, do behavioral development economists believe they have a new view of why people are poor that goes beyond past thinking on the subject, but they also believe they are in a position to resolve a long-standing policy debate in development economics (as for example between Jeffrey Sachs and William Easterly) over whether aid to developing countries is effective in addressing problems of development. Note that development aid comes in the form of cash transfers to developing countries from developed ones and international organizations and agencies. As such its disposition is largely under the jurisdiction of developing countries themselves, though donors do conditionalize this aid and give it for broadly defined purposes, such as food assistance, health, and education. What is then argued by behavioral development economists is that rather than yes or no views of aid - Sachs (2005) favors it; Easterly (2006) opposes it what they believe they can determine is how and when aid should be provided. Banerjee and Duflo in Poor Economics (Banerjee and Duflo, 2011) make the most extensive case in this regard. Using randomized control trial (RCT) field experiments, they argue they can determine at the micro-level how and when scarce aid monies ought to be used. Their paradigm example is the provision of bed nets to the poor to combat malaria, especially in Africa. Past experience with bed nets in many countries, particularly where they have been freely distributed, has met with uneven success in that those who receive them do not always make good use of them. But why has this been the case? Banerjee and Duflo worry about people's default choices. Perhaps mis-use and under-use of bed nets can be explained by people's cognitive biases. If these default choices can then be supplanted by ones that are rational in the sense of producing proper use of bed nets, then crippling problems such as malaria can be effectively addressed and aid effectively targeted. Of course, they emphasize, what cognitive biases and decision heuristics people employ are usually not easy to determine, but the promise of the RCT method is that it will make it possible to get at precisely what motivates people's choices. Then in principle it should be possible to design policies and institutional arrangements that 'nudge' people toward rational defaults. For example, in the case of bed nets, there seems to be some evidence that when people acquire their first bed nets at low subsidized prices, they are more inclined to buy and make good use of second bed nets at full prices (Banerjee and Duflo, Ibid., pp. 67-8). Since many health 
interventions depend on the willingness of individuals to make use of them - AIDS drugs are another example - the strategy of identifying the incentives that motivate people's choices potentially has wide application.

Behavioral development economics imperialism, then, begins by setting aside the conventional development economics framework in which aid agencies work through national governments to deliver such things as health services to local communities. That framework is built around explanations of noneconomic phenomena such as political relationships and customary cultural values that fall within the domains of political science, law, history, and sociology. One important dimension of this alternative framework concerns what are called collective action problems which involve the provision of nonexcludable goods, the supply of which depends on people cooperating with one another despite it being in their immediate interest not to do so. Whether people cooperate in turn often depends on whether they have reason to trust one another, and whether they have a reason to trust one another further often depends on their social proximity. This, however, is just what is missing in the development aid context, where people in local communities must determine whether they trust outsiders - a situation characterized as one of 'generalized trust' (Yamagishi, 2001) - in the person of government officials and representatives from aid agencies. The case of bed nets, then, is just such a case. It is a collective action problem because successfully combating malaria requires extensive participation from a community, and whether people cooperate in using bed nets can be influenced by how much they trust government officials and aid agency representatives who recommend their use. It is possible, of course, to minimize the collective action character of bed net use, and see this is as strictly in the individual interest of those who use them. But this overlooks how people establish what they believe to be in their self-interest, and how this can depend on not only whether they trust outsiders' advice but even whether those in their own communities have set examples in this regard. These kinds of considerations, however, are mostly at odds with behavioral development economics in virtue of its biases approach to decision heuristics, and consequently its approach is an imperialistic one in seeking to explain the non-economic as 'economic.'

Compare, then, how a development economics informed by the Gigerenzer-ABC group approach might address aid and developing country health policy. Their view of fast and frugal choice heuristics is that they are rules for solving choice problems that people regularly encounter, and are not all-purpose, onesize-fits all rules (such as 'maximize utility'), but are ecologically (rather than substantively) rational in the sense of being fit for use in specific types of circumstances. Learning, then, how people's decision heuristics influence their health requires first establishing why the rules they have are rational relative to the circumstances in which they are employed. Thus to increase use of bed nets one does not ask why people fail to be rational about their use, but rather why it is rational for them to under-use them in those circumstances. In this connection, Gigerenzer (2010) recommends we investigate what he refers to as social heuristics, or decision heuristics that people employ in environments which exhibit significant social group dynamics. Examples are imitate-your-peers, tit-for-tat, follow-an-authority, and if-there-is-a-default-do-nothing. These rules are not necessarily in play in all social circumstances, and they obviously can produce conflicting guidance to people. But they provide one way of investigating how people living in local communities in developing economies might choose whether they wish to 
cooperate with one another and the policy initiatives of outsiders. This, then, provides an alternative basis for a development economics informed by psychology, though in this case a development economics formulated in terms of such social psychology concepts as social groups, communities, social relationships within societies, etc. Needless to say, concepts such as these have little place in behavioral development economics. This raises a further question: how should we understand the relationship between the expert policy advice wish to provide and the people in developing economy societies?

I claim that behavioral development economists claiming to offer expert policy advice to developing economy societies are vulnerable to the charge of being imperialist in the social and cultural sense of that term. The concept of imperialism was originally associated with developed countries' political and economic domination of developing societies in the nineteenth and first half of the twentieth centuries, but after World War II it has also been associated with developed country efforts to impose their values, philosophies, and social and cultural practices on people in developing societies - a post-colonial cultural imperialism (see Said, 1994). Note, then, that providing expert policy advice to people in developing societies does not per se count as imperialist in this sense, since expert policy need not be formulated in a manner that suppresses or disregards social values and practices in those societies. ${ }^{8}$ It is also important to distinguish between the experts themselves and the advice they provide, since the personal attitudes of individual experts are often not culturally imperialist, and frequently quite the opposite in their awareness of and concern for cultural differences. What does, however, create grounds for the charge that behavioral development economics is imperialist in the social and cultural sense is the paternalist dimensions of its 'nudge' view of economic policy, especially when we emphasize contemporary differences between developed and developing countries. Consider, then, how the 'nudge' view of economic policy takes on different meanings in the two cases.

Developed economies, it seems fair to say, are generally more liberal economies in the sense that their societies are generally organized around market relationships. In contrast, though of course markets operate extensively in developing economies, their societies also possess many non-liberal economic relationships, some of which, such as how local communities are organized through traditional institutions, provide them cooperative solutions to collective action problems associated with nonexcludable goods provision (see for example, Panzironi and Gelber, 2012). Thus while 'nudge' paternalism in liberal market societies may be no more interventionist in people's lives than other forms of economic policy which influence their choices, in developing economies reconfiguring economic institutions and redesigning choice architectures is paternalist in a much stronger way in that it can cause changes in people's conceptions of themselves and their societies. That is, economic policy is successful in the heuristics and biases approach when it leads people to behave as rational utility maximizers even should they be disposed to act otherwise due to established trust relationships, customary practices, identification with social groups, etc. In contrast, when fast and frugal heuristics view is formulated in terms of social heuristics, it leaves the door open to development policies which build on existing social institutions. This points us to a basic difference between the how the two

\footnotetext{
${ }^{8}$ For example, Duflo, Kremer, and Robinson (2010) evaluate a program that addresses how farmers spend cash on fertilizer that emphasizes farmers' existing patterns of decision-making rather than impose pre-given views of rational finance.
} 
approaches underlie development policy, and shows the vulnerability of behavioral development economics with its heuristics and biases approach to the charge of being culturally imperialist.

\section{$5 \quad$ Economics imperialism under the impact of other disciplines}

The argument above treats behavioral development economics imperialism as an economics-pluspsychology imperialism or a social science imperialism under the leadership of economics. Why not just refer to this as economics imperialism without the more complex label, since the effect of this imperialism seems to be largely the same as economics imperialism was previously understood, that is, in each case economics imposes its discourse on subject matters previously addressed by other disciplines? Indeed, just as Becker's economics of the family applies utility maximization reasoning to household organization, which has long been explained by other social scientists in terms of sociological and psychological ideas, so behavioral development economics applies this reasoning to household organization in developing societies, as in the bed net case, which similarly has other social science explanations. However, there is an important difference between the two cases, which was tied in the discussion above to the idea of an 'in-house' imperialism which economics practices toward candidate concepts and principles being imported from other disciplines. The idea of an 'in-house' imperialism was used to explain the process of appropriation as 'domestication,' but the latter idea is of course is subject to a host of qualifications concerning the degree to which candidate other science materials are made or found to conform to what economists regard as 'economic.' At one end of the spectrum, then, it seems fair to say there are cases in which economics largely frames the other science disciplinary materials it admits; at the other end are cases in which the exporting discipline largely frames the concerns of economics. The case examined in this paper is the former sort, but to assume only one case always applies cannot be justified, since the long history of economics is not one of doctrinal continuity but rather of changing paradigms interspersed with periods of competition between rival approaches (see, Davis, 2008). ${ }^{9}$ Thus it quite possible that economics is transformed in substantive ways, including how it is defined, by its imports of other science contents. ${ }^{10}$

Under this latter scenario, it thus seems odd to speak of economics imperialism. But if it is nonetheless professional economists promoting 'economic' interpretations of non-economic phenomena, even when their theories are framed by other disciplines, it seems we are nonetheless still talking about economics imperialism. How are we to sort this all out? I suggest that we use the idea of a social science imperialism under the leadership of economics rather than the traditional economics imperialism idea for the following reasons. First, this expanded framework preserves the agency role of economists, which, as in account of experts above, tells us important things about the vehicles and

\footnotetext{
${ }^{9}$ The doctrinal continuity view flows from the Whig interpretation of history of ideas whereby contemporary figures see all history in a self-serving way as leading up to their own theories. For the late historian Mark Blaug's critique of this rationalist historiography, see Davis (2013).

${ }^{10}$ As for example argued regarding the origins of neoclassical economics by Mirowski (1989). Thus the classical economics definition of economics is different from the Robbins definition for neoclassical economics.
} 
conceptual mechanisms of an economics/social science imperialism. Second, it accommodates interand cross-disciplinary social science developments, such as the spread of cognitive science thinking in the postwar period across many disciplines, in a way that is consistent with the relative autonomy of economics (and other social sciences) in an environment in which cross-disciplinary imports have become common. Third, the 'leadership' idea tells us something about disciplinary hierarchies in social science and society, and in particular about the priority given in contemporary society to 'economic' explanations of the world. Fourth, the broader idea implicates other sciences in social and cultural imperialism carried out by developed economy science as a whole, arguably providing a better understanding of the command it exercises over developing society values and institutions. Fifth, the larger framework helps correct the over-estimation of economics' as an all-encompassing social science.

As emphasized, the arguments here depend on the assumption that economics retains its relative autonomy in an environment of imports from other sciences. But one can also consider a state of affairs in which this autonomy is only nominal and the framing of economics by other disciplines makes it difficult to think of economics as a separate science. What this might involve also seems worthy of investigation.

\section{References}

Akerlof, George and Rachel Kranton (2000) "Economics and Identity," Quarterly Journal of Economics 115 (3): 715-753.

Banerjee, Abhijit and Esther Duflo (2011) Poor Economics: A Radical Rethinking of the Way to Fight Global Poverty, New York: Public Affairs.

Benartzi, Shlomo and Richard Thaler (2004) "Save More Tomorrow: Using Behavioral Economics to Increase Employee Saving," Journal of Political Economy 112 (1): 164-87.

Bertrand, Marianne, Sendhil Mullainathan, and Eldar Shafir (2004) "A Behavioral-Economics View of Poverty," American Economic Review 94 (2): 419-23.

Bertrand, Marianne, Sendhil Mullainathan, and Eldar Shafir (2006) "Behavioral Economics and Marketing in Aid of Decision Making Among the Poor," Journal of Public Policy \& Marketing 25 (1): 8-23. 
Camerer, Colin (2006) "Behavioral Economics," Advances in Economics and Econometrics: Theory and Applications, Ninth World Congress, vol. 2, Blundell, R., Newey, W., Persson, T., eds., Cambridge: Cambridge University Press: 181-214.

Davis, John (2008) "The turn in recent economics and return of orthodoxy," Cambridge Journal of Economics, 32 (May): 349-366.

Davis, John (2011) Individuals and Identity in Economics, Cambridge: Cambridge University Press.

Davis, John (2012) “Mäki on Economics Imperialism," Economics for Real: Uskali Mäki and the Place of Truth in Economics, Jaakko Kuorikoski, Aki Lehtinen, and Petri Ylikoski, eds., London: Routledge, 2012: 203-219.

Davis, John (2013) "Mark Blaug on the Historiography of Economics," forthcoming in Erasmus Journal of Philosophy and Economics.

Duflo, Esther, Michael Kremer, and Jonathan Robinson (2011) "Nudging Farmers to Use Fertilizer: Theory and Experimental Evidence from Kenya," American Economic Review 101 (6): 2350-90.

Easterly, William (2006) The White Man's Burden: Why the West's Efforts to Aid the Rest Have Done So Much III and So Little Good, Oxford: Oxford University Press.

Fehr, Ernst, and Klaus Schmidt (1999) "A Theory of Fairness, Competition, and Cooperation," The Quarterly Journal of Economics 114 (3): 817-868.

Fine, Ben (2001) "Economics Imperialism as Kuhnian Revolution," International Papers in Political Economy 8 (2): pp. 1-58.

Fine, Ben (2002) "Economics Imperialism and the New Development Economics as Kuhnian Paradigm Shift," World Development 30 (12): pp. 2057-70.

Gigerenzer, Gerd and Reinhard Selten, eds. (2001) Bounded Rationality: The AdaptiveToolbox, Cambridge, MA: MIT Press.

Gigerenzer, Gerd (2010) "Moral satisficing: Rethinking moral behavior as bounded," Topics in Cognitive Science 2: 528-554.

Gilovich, Thomas, Dale Griffin, and Daniel Kahneman, eds. (2002) Heuristics and Biases: The Psychology of Intuitive Judgment, Cambridge: Cambridge University Press.

Heukelom, Floris (2011) "Behavioral Economics," in The Elgar Companion to Recent Economic Methodology, J. Davis and D. Hands, Cheltenham: Edward Elgar, 19-38.

Kahneman, Daniel and Amos Tversky (1996) "On the Reality of Cognitive Illusions," Psychological Review 103 (3): 582-591.

Karlan, Dean (2010) "Helping the Poor Save More," Stanford Social Innovation Review, Winter: 48-52. 
Lewis, Oscar (1969) "Culture of Poverty," in On Understanding Poverty: Perspectives from the Social Sciences, D. Moynihan, ed., New York: Basic Books: pp. 187-220.

Mäki, Uskali (2009) "Economics Imperialism: Concept and Constraints," Philosophy of the Social Sciences 39 (September): 351-380,

Manser, Marilyn and Murray Brown (1980) "Marriage and Household Decision Making: A Bargaining Analysis," International Economic Review 21 (1): 31-44.

McElroy, Marjorie B. and Mary Jean Horney (1981) "Nash Bargained Household Decisions," International Economic Review 22 (2): 333-49.

Mirowski, Philip (1991) More Heat than Light: Economics as Social Physics, Physics as Nature's Economics, Cambridge: Cambridge University Press.

Panzironi, Francesca and Katharine Gelber, eds., (2012) The Capability Approach: Development practice and public policy in the Asia-Pacific region, London: Routledge.

Sachs, Jeffrey (2005) The End of Poverty: Economic Possibilities for Our Time, New York: Penguin.

Said, Edward (1994) Culture and Imperialism, New York: Alfred A. Knopf.

Schmallensee, Richard (1988) “Industrial Economics: An Overview," Economic Journal 98 (392): 643-681.

Sen, Amartya (1985) "Goals, Commitment, and Identity," Journal of Law, Economics and Organization 1 (2): 341-55.

Simon, Herbert (1956) "Rational Choice and the Structure of the Environment," Psychological Review 63: 129-38.

Simon, Herbert (1991) Models of My Life, New York: Basic Books.

Thaler, Richard (1999) “Mental Accounting Matters," Journal of Behavioral Decision Making 12 (3): 183206.

Thaler, Richard (2000) "From Homo Economics to Homo Sapiens," Journal of Economic Perspectives, 14 (1): 133-141.

Thaler, Richard and Cass Sunstein (2008) Nudge: Improving Decisions about Health, Wealth, and Happiness, rev. expanded edition, New Haven: Yale University Press.

Velupillai, Vela and Ying Fang Kao (forthcoming) "Herbert Simon," in G. Faccarello and H. Kurz, Handbook of the History of Economic Analysis, Cheltenham: Edward Elgar.

Yamagishi, Toshio (2001) "Trust as a form of social intelligence," in K. Cook, ed., Trust in Society, New York: Russell Sage: 121-47. 